\title{
TRANSARTICULAR FIXATION FOR SEVERELY DISPLACED SUPRACONDYLAR FRACTURES IN CHILDREN
}

\author{
DAVID A. A. ARCHIBALD, J. A. ROBERTS, M. G. H. SMITH
}

From the Royal Hospital for Sick Children, Glasgow

\begin{abstract}
We have reviewed 34 children who had been treated by open reduction through a medial incision and transarticular pinning for a severely displaced supracondylar fracture of the humerus.

Follow-up ranging from nine months to 20 years showed that 27 of 34 elbows (79\%) had excellent or good results, with satisfactory resolution of neurovascular problems and no complications due to the method of treatment.
\end{abstract}

The management of severely displaced, unstable supracondylar fractures of the humerus in children continues to be controversial. This is shown by the variety of conservative and operative treatments which have been advised.

Non-operative management by straight traction with the elbow in extension was first reported by Dunlop (1939); this method has recently been reviewed by Piggot, Graham and McCoy (1986). Treatment in extension in plaster has been described (El-Sharkawi and Fattah 1965), and in a Thomas splint (Bosanquet and Middleton 1983). Dunlop later advised that traction should be applied with the elbow in flexion (Allen and Gramse 1945).

The use of skeletal traction on a flexed elbow has been described by Smith (1947), who used a transverse Kirschner wire through the ulna, and by Palmer et al (1978) who used an olecranon screw. Closed reduction followed by percutaneous pinning has been reported by several authors (Swenson 1948; Flynn, Matthews and Benoit 1974; Ariño et al 1977; Nacht et al 1983).

A variety of approaches have been advised for open reduction. The posterior approach (Sandegård 1943; Madsen 1955), has been criticised as likely to result in loss of extension. The anteromedial approach, fixing the fracture with a pin through each condyle as fixation, was

D. A. A. Archibald, FRCS, Orthopaedic Registrar Royal Infirmary, Castle Street, Glasgow G4 OSF, Scotland

J. A. Roberts, FRCS, Orthopaedic Senior Registrar Western Infirmary, Byres Road, Glasgow G11 6NJ, Scotland M. G. H. Smith, FRCS, Consultant Orthopaedic Surgeon Royal Hospital for Sick Children, Yorkhill, Glasgow G3 8SJ, Scotland

Correspondence should be sent to Mr D. A. A. Archibald.

(C) 1991 British Editorial Society of Bone and Joint Surgery 0301-620X/91/1047\$2.00

J Bone Joint Surg [Br] 1991; 73-B: 147-9.
Table I. Radiographic classification of supracondylar fractures of the humerus (Holmberg 1945)

\begin{tabular}{ll}
\hline Grade & \\
\hline 1 & Undisplaced or minimally displaced greenstick fractures \\
2 & $\begin{array}{l}\text { Medial or lateral displacement on anteroposterior view } \\
\text { Good contact on lateral view }\end{array}$ \\
3 & Rotational displacement \\
4 & $\begin{array}{l}\text { Complete displacement } \\
\text { No contact on the lateral view }\end{array}$ \\
\hline
\end{tabular}

advocated by Carcassonne, Bergoin and Hornung (1972), who reported excellent or good results in 39 of 40 patients. Danielsson and Pettersson (1980) recommended a medial exposure with condylar pin fixation through a small lateral incision. Weiland et al (1978) performed the reduction through a lateral exposure, with a smaller medial incision for the insertion of the second wire. Ramsey and Griz (1973) used a medial approach with two crossed wires into each condyle.

We now report the use of open reduction and internal fixation by a transolecranon pin, as described by Childress (1972). This method has been used by the senior author (MGHS) over a 20-year period for 42 severely displaced or compound supracondylar fractures in children (grade 4 of Holmberg 1945, Table I). To our knowledge there has been no previous report of the results of this method in a series of patients.

\section{PATIENTS AND METHODS}

Open reduction and percutaneous pinning was used to treat 42 children presenting to the Royal Hospital for Sick Children in Glasgow with severe supracondylar humeral fractures. Their average age was seven years three months, ranging from one year seven months to 12 
years two months. There were 23 boys and $59 \%$ of the fractures involved the non-dominant arm. There were three open fractures, and 14 patients had some clinical evidence of neurovascular complications: four lacked a palpable radial pulse, four had radial nerve palsies (two partial, two total), and eight had median nerve palsies. Sixteen patients, most of them early in the series, had had attempts at closed reductions, but 26 were treated primarily by immediate open reduction for the following reasons:

1) failed closed reduction may increase injury to soft tissue, and damage the bony interdigitations which help in accurate open reduction;

2) soft tissues can be decompressed by evacuation of the haematoma and haemostasis is possible;

3) open reduction ensures against soft tissue or neurovascular interposition; and

4) anatomical reduction is possible.

Operative technique. Using general anaesthesia and a high tourniquet, the fracture is exposed through an incision centred on the medial epicondyle. The ulnar nerve is identified and protected. Brachialis is defined and swept forward, thus protecting and, if necessary, freeing the median nerve and brachial artery. The fracture haematoma is evacuated, and the bone ends cleaned so that it is relatively easy to reduce the fracture anatomically.

Table II. Results of treatment of supracondylar fractures of the humerus (Flynn et al 1974)

\begin{tabular}{lll}
\hline Result & $\begin{array}{l}\text { Function } \\
\text { (loss of movement) }\end{array}$ & $\begin{array}{l}\text { Appearance (change } \\
\text { in carrying angle) }\end{array}$ \\
\hline Excellent & $0^{\circ}$ to $5^{\circ}$ & $0^{\circ}$ to $5^{\circ}$ \\
Good & $6^{\circ}$ to $10^{\circ}$ & $6^{\circ}$ to $10^{\circ}$ \\
Fair & $11^{\circ}$ to $15^{\circ}$ & $11^{\circ}$ to $15^{\circ}$ \\
Poor & $>15^{\circ}$ & $\begin{array}{l}>15^{\circ} \text { (cubitus } \\
\text { varus) }\end{array}$ \\
\hline
\end{tabular}

The elbow is flexed to $90^{\circ}$ and a $2.4 \mathrm{~mm}$ guide wire is passed percutaneously through the olecranon, across the elbow joint, into the distal fracture fragment and up the centre of the humeral shaft. Care is required to avoid the wire leaving the bone at the olecranon fossa. The tourniquet is then released, the circulation is checked and haemostasis is secured. The wound is closed and the pin bent to prevent migration.

A plaster back slab is used for three weeks, and the plaster and pin are then removed in the out-patient clinic. Light general anaesthesia was required for some of the earlier cases.

Clinical review. All the patients who had been treated by this method were requested to attend for clinical and radiological review: 34 of the original 42 were seen. Six patients were lost to follow-up and two were excluded because follow-up was less than six months.

Subjective opinions were recorded and measurements made of elbow movements and carrying angle, using the uninjured side as control. Standard radiographs were taken. Each elbow was scored for function by the alteration in the flexion/extension arc and for appearance by the change in the carrying angle (Flynn et al 1974, Table II). The overall result was recorded as the worse of the two scores.

\section{RESULTS}

The average stay in hospital was four days (1 to 15); the longer periods were related to failed attempts at closed manipulation, early inexperience with the method, and associated injury or neurovascular damage.

Two patients had early postoperative complications. In one case, the guide wire migrated proximally and required general anaesthesia for removal from just under the skin; in the other a mild pin track infection settled rapidly after the wire was removed. All wounds healed by primary intention. One child developed a Volkmann's ischaemic contracture. This was attributed to a delay of eight hours between the injury and operation, due to attempts at closed reduction at the referring hospital.

The 34 elbows were reviewed at an average followup of 6.8 years (range nine months to 20 years). The results are given in Table III. In one child the pin fixation had missed the proximal humerus, allowing a $20^{\circ}$ varus deformity which later required a supracondylar osteotomy. This was a failure of technique, and although the final result was a normal carrying angle and only a $10^{\circ}$ loss of extension/flexion, the result was classified as poor. Only one patient had loss of more than $15^{\circ}$ of the extension/flexion arc, but five had a change in carrying angle of more than $10^{\circ}$.

Taking the worse score for either angle, $79 \%$ of the patients had an excellent or good result, with loss of less than $11^{\circ}$ of arc and less than $11^{\circ}$ change in carrying angle. All but two of the 14 patients with nerve injuries recovered fully; two had residual partial paresis of the median nerve.

\section{DISCUSSION}

Many different methods have been proposed for the treatment of supracondylar fractures. Simple closed manipulation has been considered to be adequate, but with severe displacement the results may be both cosmetically and functionally unacceptable. Piggot et al (1986) confirmed that closed manipulation of Holmberg grade 4 fractures produces poor results; his treatment by traction produced good cosmetic results, but sometimes at the expense of function. Treatment by traction may leave posterior displacement of the distal fragment; remodelling is required to correct this. There is also the 
Table III. Results at late review of 34 elbows

\begin{tabular}{lcc}
\hline & & Number \\
\hline Function & $0^{\circ}$ to $5^{\circ}$ & 27 \\
(loss of movement) & $6^{\circ}$ to $10^{\circ}$ & 4 \\
& $11^{\circ}$ to $15^{\circ}$ & 2 \\
& $>15^{\circ}$ & 1 \\
& & \\
& $0^{\circ}$ to $5^{\circ}$ & 23 \\
Appearance & $6^{\circ}$ to $10^{\circ}$ & 6 \\
(change in carrying angle) & $11^{\circ}$ to $15^{\circ}$ & 0 \\
& $>15^{\circ}$ & 5 \\
& & \\
& Excellent & 20 \\
Overall score & Good & 7 \\
& Fair & 1 \\
& Poor & 6 \\
\hline
\end{tabular}

disadvantage of prolonged hospitalisation and the need for careful, experienced, observation during this time.

For many years open reduction of elbow fractures has been believed to cause severe stiffness (Blount 1954). However, this has arisen mainly after lateral or posterior approaches or prolonged periods of immobilisation. A medial approach seems to give very few problems with stiffness. Closed percutaneous wiring of these fractures has many advocates (Flynn et al 1974; Ariño et al 1977; Nacht et al 1983), but this is difficult in the presence of severe swelling and there is a risk of pin track infection and of damage to nerves.

The technique we report allows accurate reduction of these severe fractures, with fixation that has the advantage of including the joint. The use of a relatively thick $2.4 \mathrm{~mm}$ guide wire has avoided fracture of the transarticular fixation, and we have seen no evidence on any radiograph of any resulting articular damage.

Open reduction by a medial approach and fixation by a single transarticular pin is a safe and reliable method for the primary management of severely displaced (Holmberg grade 4) supracondylar fractures in children.

No benefits in any form have been received or will be received from a commercial party related directly or indirectly to the subject of this article.

\section{REFERENCES}

Allen PD, Gramse AE. Transcondylar fractures of the humerus treated by Dunlop traction. Am J Surg 1945; 67:217-27.

Ariño VL, Lluch EE, Ramirez AM, Ferrer J, Rodriguez L, Baixauli F. Percutaneous fixation of supracondylar fractures of the humerus in children. J Bone Joint Surg [Am] 1977; 59-A :914-6.

Blount WP. Fractures in children. Baltimore: Williams \& Wilkins:1954.

Bosanquet JS, Middleton RW. The reduction of supracondylar fractures of the humerus in children treated by traction-in-extension: a review of 18 cases. Injury 1983; 14:373-80.

Carcassonne M, Bergoin M, Hornung H. Results of operative treatment of severe supracondylar fractures of the elbow in children. $J$ Pediatr Surg 1972; 7:676-9.

Childress HM. Transarticular pin fixation in supracondylar fractures at the elbow in children. J Bone Joint Surgery [Am] 1972; 54-A :1548 52 .

Danielsson L, Pettersson H. Open reduction and pin fixation of severely displaced supracondylar fractures of the humerus in children. Acta Orthop Scand 1980:51:249-55.

Dunlop J. Transcondylar fractures of the humerus in childhood. $J$ Bone Joint Surg 1939; $21: 59-73$

El-Sharkawi AH, Fattah HA. Treatment of displaced supracondylar fractures of the humerus in children in full extension and supination. J Bone Joint Surg [Br] 1965; 47-B:273-9.

Flynn JC, Matthews JG, Benoit RL. Blind pinning of displaced supracondylar fractures of the humerus in children: sixteen years experience with long-term follow-up. J Bone Joint Surg [ Am] 1974 56-A:263-72.
Holmberg L. Fractures of distal end of the humerus in children. Acta Chir Scand 1945; 92 Suppl 103:1-69.

Madsen E. Supracondylar fractures of the humerus in children. $J$ Bone Joint Surg [Br] 1955; 37-B; 241-5.

Nacht JL, Ecker ML, Chung SMK, Lotke PA, Das M. Supracondylar fractures of the humerus in children treated by closed reduction and percutaneous pinning. Clin Orthop 1983; 177:203-9.

Palmer EE, Niemann KMW, Vesely D, Armstrong JH. Supracondylar fracture of the humerus in children. J Bone Joint Surg [Am] 1978 60-A :653-6.

Piggot J, Graham HK, McCoy GF. Supracondylar fractures of the humerus in children : treatment by straight lateral traction. $J$ Bone Joint Surg [ Br] 1986; 68-B:577-83.

Ramsey RH, Griz J. Immediate open reduction and internal fixation of severely displaced supracondylar fractures of the humerus in children. Clin Orthop 1973; 90:130-2.

Sandegàrd E. Fracture of the lower end of the humerus in children Treatment and end results. Acta Chir Scand 1943-4:89:1-16.

Smith FM. Kirschner wire traction in elbow and upper arm injuries. Am J Surg 1947; $74: 770-87$

Swenson AL. The treatment of supracondylar fractures of the humerus by Kirschner-wire transfixion. J Bone Joint Surg [Am] 1948; 30A :993-7.

Weiland AJ, Meyer S, Tolo VT, Berg HL, Mueller J. Surgical treatment of displaced supracondylar fractures of the humerus in children analysis of fifty-two cases followed up for five to fifteen years. $J$ Bone Joint Surg [ Am] 1978; 60-A :657-61. 